\title{
Kendali Komunikasi Tim Produksi Program "Tikaudjo" pada Radio Bahana 101.8 FM Jakarta
}

\author{
Ketut Wiriyanto ${ }^{1}$, Ahmad Toni ${ }^{1}$ \\ ${ }^{1}$ Magister Ilmu Komunikasi, Universitas Budi Luhur \\ Jl. Ciledug Raya No.99, Petukangan Utara, Kec. Pesanggrahan, Kota Jakarta Selatan \\ Daerah Khusus Ibukota Jakarta 12260 - Indonesia \\ Email : 'ketutwiriyantowork@gmail.com, ${ }^{1}$ ahmad.toni@budiluhur.ac.id
}

Received: Januari 2021; Accepted: April 2021; Published: Juni 2021

\begin{abstract}
This study aims to determine the organizational control team of the TikaUdjo production program. The proposed research statement is what the organization controls on the TikaUdjo program production team. The theory that researchers use to obtain data uses organizational control theory. The research method used is a descriptive qualitative approach with a post-positivism paradigm. The research subjects are producers, assistant producers and broadcasters in obtaining accurate data, and the object of research is the control of the production team of the TikaUdjo program organization on Bahana Radio 101.8 FM Jakarta. Collecting data obtained through in-depth interviews and participant observation conducted on key informants and informants. Other data were obtained from Key Informants, informants, and various other data sources. The results of this study indicate that the TikaUdjo program production team at Radio Bahana 101.8 FM Jakarta consistently implements four concepts of organizational control theory by Phillip Tompkins, George Cheney, and their colleagues. The conclusion of this research is that the production team performs the four control theory concepts quite well, and it can be accounted for in which these four theoretical concepts are the processes that the production team does in producing the event program.
\end{abstract}

Keywords: Organizational Control; Production Team; Quantitative.

\begin{abstract}
Abstrak
Penelitian ini bertujuan untuk mengetahui tim kontrol organisasi program produksi TikaUdjo. Pernyataan penelitian yang diusulkan adalah apa yang organisasi kontrol pada tim produksi program TikaUdjo. Teori yang peneliti gunakan untuk mendapatkan data menggunakan teori kontrol organisasi. Metode penelitian yang digunakan adalah pendekatan kualitatif deskriptif dengan paradigma postpositivisme. Subjek penelitiannya adalah Produser, Assistant produser dan juga penyiar dalam mendapatkan data yang akurat, serta objek penelitian adalah kontrol tim produksi organisasi program TikaUdjo pada Radio Bahana 101.8 FM Jakarta. Pengumpulan data yang diperoleh melalui wawancara mendalam dan observasi partisipan dilakukan kepada informan kunci dan informan. Data lain diperoleh dari Key Informan, informan, dan berbagai sumber data lainnya. Hasil penelitian tersebut menyebutkan bahwa tim produksi program TikaUdjo pada Radio Bahana 101.8 FM Jakarta melakukan empat konsep teori kontrol organisasi Phillip Tompkins, George Cheney, dan rekan-rekannya dengan konsisten. Kesimpulan dari penelitian ini adalah tim produksi melakukan empat konsep teori kontrol dengan cukup baik, dan dapat dipertanggung jawabkan di mana empat konsep teori ini adalah proses dimana tim produksi lakukan dalam menghasilkan program acara.
\end{abstract}

Kata Kunci: Kontrol Organisasi; Tim Produksi; Kuallitatif.

doi: https://doi.org/10.51544/jlmk.v5i1.1679

(C) 2021 Jurnal Lensa Mutiara Komunikasi. This is an open access article under the CC BY-SA license

Website: http://e-journal.sari-mutiara.ac.id/index.php/JLMI/

http://e-journal.sari-mutiara.ac.id 


\section{PENDAHULUAN}

Radio sebagai salah satu media komunikasi yang efektif bagi masyarakat karena jangkauannya yang luas. Radio juga berfungsi sebagai alat penghibur dan penyampaian informasi yang dapat menemani kegiatan para pendengarnya dengan berupa suara. Radio bersifat menarik, karena dukungan unsur musik, kata-kata atau bahasa yang digunakan terkesan lebih akrab karena sifat siarannya yang mudah dan ringan disertakan permainan efek suara.Pendengar radio dapat menikmati berita, musik, kuis, serta bermacam acara yang dikemas oleh stasiun radio sambil melakukan aktifitas lain. Radio juga salah satu media yang efektif bagi masyarakat karena jangkauannya yang cukup luas dan dapat menembus berbagai lapisan masyarakat. Radio juga disebut sebagai sahabat yang dapat menemani kegiatan sehari-hari para pendengarnya, karena berfungsi sebagai alat penghibur, penyampai informasi, dan melaksanakan fungsi pendidikan bagi masyarakat.(Pingkan Agustine, Liliyana, 2019).

Beraneka pesan yang disampaikan media massa seperti koran, majalah, radio, Televisi, Film dan internet dapat dijadikan sebagai alternatif bagi masysrakat untuk memperoleh berbagai informasi. Sumber informasi yang akan diperoleh masyarakat dengan kondisi tidak mampu dan tidak suka membaca maka Radio dijadikan sumber. Radio merupakan salah satu media massa yang disukai oleh masyarakat Indonesia untuk mendapatkan hiburan maupun informasi. Selain itu, radio yang mempunyai karakteristik akrab, membuat pendengar merasa informasi dan hiburan yang diterima lebih spesifik. Oleh karena itu, radio tetap ada meskipun telah hadir media baru, internet. Bahkan, Nielsen Radio Audience Measurement mencatat pendengar radio masih menempati angka 38\%, hal tersebut menunjukan bahwa radio masih memiliki pendengar setia. Pendengar radio rata-rata mendengarkan melalui telepon genggam, walaupun pengguna media baru memiliki angka lebih tinggi, yakni 40\%. (Lubis, 2017).

Radio Bahana 101.8 FM berawal dari pemikiran sederhana bahwa semua orang menyukai lagu bagus, dan pasti akan terus menyanyikannya dalam keseharian. Bahana FM adalah stasiun radio dengan jangkauan jabodetabek, adult contemporary $(A C)$ dengan $80 \%$ musik Indonesia dan 20\% musik Barat. Dengan komposisi content: 60\% Music, 30\% Entertainment, 10\% News \& Information. Hadir untuk memberikan yang terbaik bagi pendengar (yang disebut dengan "TEMAN BAHANA") usia 25-35 tahun, pria dan wanita kelas menengah, SES A-B-C, yang menikmati hidup seperti menikmati lagu favorit mereka (bahana fm, 2020). Salah satu program radio Bahana FM adalah program radio bernama "Tika Udjo On Bahana FM". Tika Udjo On Bahana FM yang baru dimulai dua tahun belakangan ini, dalam pencarian konsepnya Produser tidak sembarangan untuk menjadikan mereka sebagai penyiar, karena tugas penyiar itu pun harus sesuai dengan ide yang telah dibuat oleh Produser.

Maka dari itu, Produser memilih Tika Panggabean dan Udjo yang juga merupakan personil grup Project Pop, karena memiliki segmentasi usia yang mendekati sesuai dengan pendengar Bahana dan pemetaan serta kerangka konsep sehingga terbentuk program Tika Udjo On Bahana FM. Selain keunikan yang terdapat di komposisi siaran, program Tika Udjo On Bahana FM selalu menyajikan dan menyiarkan isi siaran yang bervariatif pada setiap harinya seperti menggunakan kata - kata popular sehari - hari dalam siaran serta membahas sesuatu yang update dan membawakan gaya siaran yang ringan agar bisa mudah dinikmati pendengar sesuai dengan target. Hal itu sangat dipengaruhi oleh strategi pembuatan program yang dilakukan oleh Produser Tika Udjo On Bahana FM. 


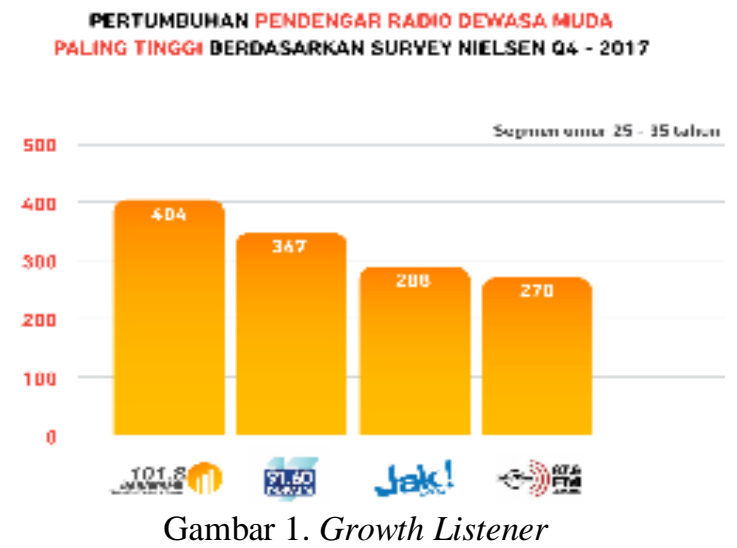

Setiap perusahaan atau instansi pasti memiliki kontrol dalam menjalankan operasional perusahaan atau instansi. Kontrol ini di fungsikan agar perusahaan berjalan sesuai dengan aturan yang telah disepakati. Kontrol yang telah ditetapkan oleh perusahaan akan membuat semua orang di dalam perusahaan mulai dari pimpinan hingga karyawan akan disiplin dan menaati semua peraturan. Kontrol di dasari oleh kekuasaan, karena kekuasaan selalu ada dalam organisasi dan tidak dapat di hindari. Penggunaan kontrol pada hubungan interpersonal dan kerja sama tim adalah sebuah cara untuk memberikan bentuk disiplin yang akan mempertahankan susunan dan konsistensi melalui kekuasaan. Jika suatu perusahaan mengalami penurunan atau krisis pun kontrol tetap harus dilakukan oleh perusahaan. Kontrol yang dibuat di masa krisis digunakan untuk menyelesaikan krisis tersebut. Kontrol proses produksi pada bahana 101.8 FM memiliki kinerja tersendiri tetapi tetap saling berkoordinasi dengan baik satu sama lain. Produser, Assistent Produser, penyiar, music director, dan staf produksi lainnya yang akan diarahkan oleh seorang atasan dari masing- masing divisi. Tugasnya adalah membuat sebuah alur dari program acara radio supaya tetap bisa dinikmati.

Melihat banyaknya kontrol organisasi yang dilakukan oleh Tim Produksi TikaUdjo pada Radio bahana 101.8 FM jakarta, Peneliti melihat banyaknya kontrol organisasi yang diterapkan Tim Produksi pada saat mulai pra produksi, produksi, dan pasca produksi untuk membuat sebuah program acara radio yang layak untuk diperdengarkan. Maka hal itu membuat Peneliti untuk meneliti bentuk kendali apa saja yang akan dilakukan oleh sebuah Tim Produksi. Oleh karena itu, Peneliti mengangkat judul "Kendali Organisasi Tim Produksi "TikaUdjo" Pada Radio Bahana 101,8 FM Jakarta. Manfaat penelitian dari segi Manfaat Teoritis Penelitian ini diharapkan bisa memberikan sumbangan pemikiran pada ilmu komunikasi terutama dalam penelitian kendali organisasi yang terjadi di dalam suatu program acara radio. Manfaat Praktis Penelitian ini diharapkan bisa menjadi bahan evaluasi dalam kendali organisasi yang dilakukan oleh Tim Produksi dalam membuat isi dan konten pada sebuah program acara radio.

\section{TINJAUAN LITERATUR}

Komunikasi massa ialah komunikasi yang menggunakan media massa dalam hal ini media massa modern yang terdiri dari surat kabar, majalah, radio, televisi, dan film. Dapat dikatakan media massa apabila khalayak secara serempak memperhatikan pesan yang disampaikan media itu pada saat yang sama. Pesan-pesannya bersifat umum, disampaikan secara cepat, serentak dan selintas (khususnya media elektronik) (Mulyana, 2005).

Media dalam komunikasi massa dibagi atas dua jenis yaitu, media cetak dan elektronik. Media massa mampu menimbulkan keserempakan di antara khalayak yang sedang 
memperhatikan pesan yang dilancarkan oleh media tersebut (Effendy, 2013), salah satunya media elektronik yaitu radio. Menurut (Riswandi, 2009), penyiaran radio adalah media komunikasi masa dengan yang menyalurkan gagasan informasi dalam bentuk suara secara umum dan terbuka, berupa program yang teratur dan berkesinambungan. Radio berasal dari kata Radios yang berarti benda-benda elektronika yang menciptakan suara untuk berkomunikasi (Sanityastuti, 1997). Radio merupakan alat menyampaikan informasi dengan memanfaatkan adanya gelombang elektromagnetik.

Banyaknya disiplin ilmu yang telah memberikan masukan terhadap perkembangan ilmu komunikasi menyebabkan munculnya berbagai macam definisi tentang komunikasi. Istilah komunikasi atau communication berasal dari bahasa Latin, yaitu communicates yang berarti berbagi atau menjadi milik bersama. Kata sifatnya communis yang bermakna umum atau bersama-sama. Dengan demikian, komunikasi menurut Lexicographer (ahli kamus bahasa), menunjuk pada suatu upaya yang bertujuan berbagi untuk mencapai kebersamaan (M, 2009).

Menurut Book ada sebuah definisi yang dibuat oleh kelompok sarjana komunikasi yang mengkhususkan diri pada studi komunikasi antar manusia (human communication) yang menyatakan bahwa: "Komunikasi adalah suatu transaksi, proses simbolik yang menghendaki orang-orang mengatur lingkungannya dengan (1) membangun hubungan antar sesama manusia (2) melalui pertukaran informasi (3) untuk menguatkan sikap dan tingkah laku orang lain (4) serta berusaha mengubah sikap dan tingkah laku itu" (Muhammad, 2007).

Sedangkan Louis Forsdale, seorang ahli komunikasi dan pendidikan mendefinisikan komunikasi sebagai berikut: "communication is the process by which a system is established, maintained, and altered by means of shared signals that operate according to rules". Definisi tersebut dapat diterjemahkan sebagai berikut, komunikasi adalah suatu proses memberikan signal menurut aturan tertentu, sehingga dengan cara ini suatu sistem dapat didirikan, dipelihara, dan diubah (Hardjana, 2016).

Teori ini dikemukakan oleh Philip Tompkins dan George Chene. Tompkins dan Cheney mengatakan bahwa mereka tertarik dalam cara-cara komunikasi biasa membentuk kendali atas pegawai. Kendali dinyatakan dalam organisasi dengan empat cara. Pertama, kendali sederhana (simple control), atau penggunaan kekeuasaan yang langsung dan terbuka. Kedua, kendali teknis (technical control), atau penggunaan alat-alat dan teknologi. Bentuk kendali yang ketiga adalah birokrasi yang merupakan penggunaan prosedur organisasi dan aturan-aturan formal. Keempat adalah kendali konsertif (concertive control), yaitu penggunaan hubungan interpersonal dan kerjasama tim sebagai sebuah cara kendali. Dalam organisasi konsertif, aturan dan regulasi yang tertulis jelas, digantikan oleh pemahaman pemaknaan nilai, objektif, dan cara-cara pencapaian bersama sejalan dengan apresiasi yang mendalam untuk misi organisasi (Littlejohn, 2009).

Menurut Tompkins dan Cheney, dalam organisai kontemporer, kendali konsertif dapat dicapai dalam empat cara. Pertama, kendali ini melibatkan metode yang tidak menonjol. Disiplin tidak harus jelas atau 22 disadari, tapi merupakan bagian dari kegiatan sehari-hari organisasi yang berjalan terus. Kedua, disiplin dihasilkan secara kolaboratif. Anggota organisasi bekerja bersama untuk membuat kegiatan-kegiatan normal, untuk membuat standar, atau sebuah disiplin. Ketiga, disiplin merupakan bagian dari hubungan sosial. Apa yang orang katakana dan lakukan kepada orang lain diatur oleh dan menghasilkan kegiatan yang ternormalkan. Keempat, cara kendali yang paling efektif didasarkan pada nilai-nilai yang mendorong anggota organisasi untuk mendapatkan hal paling mendasar yang mereka perjuangkan. Hal ini dapat meliputi uang, waktu, pencapaian, pemahaman kerja sama tim, dan sebagainya (Littlejohn, 2009). 


\section{METODE PENELITIAN}

Paradigma yang digunakan dalam penelitian ini adalah paradigma post-positivisme, tujuannya karena paradigma post-positivisme memiliki banyak kemungkinan yang dapat diketahui dalam penelitian kendali organisasi yang dilakukan tim produksi pada program Tika dan Udjo pada radio bahana Jakarta, sebab bukan hanya satu kendali saja yang digunakan key informan dan bukan hanya satu orang saja yang melakukan wawancara. Sehingga jawaban dari key informan dan informan tersebut terdapat banyak kemungkinan Dalam penelitian ini. Peneliti menggunakan mengunakan pendekatan kualitatif dengan jenis penelitian analisis desktiptif untuk mengamati suatu fenomena, mengumpulkan dan menyajikan hasil penelitian dengan menggunakan metode wawancara mendalan dan metode observasi partisipan dalam pembahasannya.

Subjek dalam penelitian ini adalah Tim Produksi program acara tikaudjo pada radio bahana Jakarta, khususnya adalah produser (Ugi lestari Widyabahri) program tikaudjo. Peneliti memilih produser karena dalam penelitian ini peneliti ingin menjelaskan terkait kendali organisasi apa saja yang dilakukan Tim Produksi pada program tikaudjo. Sebagai komunikator, seorang pemimpin Program, Produser, atau administrator harus memilih salah satu berbagai metode dan teknik komunikasi yang disesuaikan dengan situasi pada waktu komunikasi dilancarkan. (Sembiring \& Sugianto, 2018). Selain itu produser juga penulis yakini memiliki cara tersendiri untuk berkomunikasi dengan tim produksi tikaudjo, dapat melalui komunikasi interpersonal, individu dapat berusaha membina hubungan baik dengan individu lainnya, sehingga menghindari dan mengatasinya terjadinya konflik- konflik di antara individu-individu tersebut.(Maghfiroh \& Syaf, 2019) Disinilah peran komunikasi sangatlah penting dalam menyampaikan sebuah informasi kepada tim produksi dan peneliti melihat bahwa Ugi Lestari Widyabahri selaku produser memiliki kemampuan komunikasi yang baik. Komunikasi merupakan suatu kekuatan yang luar biasa dalam kehidupan organisasi. Komunikasi dalam organisasi menjadi suatu sistem aliran yang menghubungkan dan membangkitkan kinerja antar bagian dalam organisasi, sehingga menghasilkan sinergi. Jika salah dalam pemberian instruksi, salah dalam penafsiran perintah atau tugas dari atasan, maka akan menjadi fatal dalam mekanisme kerja organisasi atau perusahaan (Masmuh, 2008). Penelitian ini menggunakan data primer dan data sekunder untuk mendukung dan memperkuat hasil penelitian. Data primer adalah Sumber primer adalah sumber data yang langsung memberikan data kepada pengumpul data (Sugiono, 2010).

Teknik pengumpulan data yang digunakan adalah dengan wawancara mendalam bersama Tim Produksi program tikaudjo di Radio Bahana dan melakukan observasi partisipan. Data sekunder merupakan sumber yang tidak langsung memberikan data kepada pengumpul data, misalnya lewat orang lain atau lewat dokumen (Sugiono, 2010).

Pada teknik analisis data, proses yang dilakukan oleh peneliti dalam penelitian ini adalah dengan cara pengumpulan data untuk mencari, menata dan merumuskan kesimpulan secara sistematis dari hasil wawancara key informan dan informan, serta observasi partisipan yang peneliti lakukan. Mengumpulkan data-data yang diperlukan sebagai acuan, yaitu mengenai gambaran umum kendali organisasi Tim Produksi pada program tikaudjo di radio bahana Jakarta.

Dalam penelitian, Peneliti mengukur kebenaran data atau validitas data yang dikumpulkan selama penelitian berlangsung. Uji validitas data yang dilakukan Peneliti menggunakan Triangulasi Sumber, karena dengan menggunakan Triangulasi Sumber peneliti 
dapat menggali kebenaran informasi tertentu melalui berbagai metode dan sumber perolehan data. Pengumpulan data melalui wawancara dengan Produser sebagai Key Informan dan tambahan informasi dengan kedua Informan yaitu Assistant Produser dan Penyiar pada program TikaUdjo Pada Radio Bahana 101.8 FM Jakarta.

\section{HASIL DAN PEMBAHASAN}

Kendali Sederhana (simple control). Penggunaan kekuasaan langsung dan terbuka. Kekuasaan adalah kemampuan untuk mempengaruhi pihak lain agar berpikir dan berperilaku sesuai dengan kehendak yang mempengaruhi. Kekuasaan langsung merupakan pemanfaatan untuk mempengaruhi pembuat dan pelaksana keputusan melalui perantara pihak lain yang mempunyai pengaruh lebih besar terhadap pembuat dan pelaksana keputusan tersebut. Konsep kendali sederhana yang dilakukan oleh semua anggota Tim Produksi sesuai dengan teori Kendali Organisasi Philip Tomkins dan rekan-rekannya sudah diterapkan dan dilakukan dengan baik oleh seluruh anggota Tim Produksi TikaUdjo Bahana 101.8 FM Jakarta.

Pengambilan keputusan yang dibuat dan dilakukan Tim Produksi program TikaUdjo merupakan hasil kesepakatan bersama setelah melakukan meeting yang diadakan setiap minggunya. Di dalam pengambilan keputusan Produser mempunyai kekuasaan besar terhadap pengambilan keputusan pada hasil meeting. Hasil meeting yang sudah ada, akan ditulis dan dirancang oleh Assistent Produser sesuai dengan setiap segmen yang ada untuk mendapatkan acc dari Produser. Kalau ada yang tidak sesuai dengan apa yang sudah direncakan biasanya Produser akan langsung membicarakannya kembali dengan Assistent Produser.

Kendali Teknis (technical control). Kendali ini merupakan kendali dalam penggunaan alat-alat dan teknologi. Contohnya, jika karyawan diberikan sebuah telpon seluler dan diperintahkan untuk menggunakannya dalam pekerjaan mereka, maka mereka dalam kendali teknis karena telpon tersebut. Tujuan menerapkan konsep kendali teknis ini adalah untuk memudahkan setiap anggota mendapatkan informasi dalam bekerjasama agar lebih efektif dan efisien.

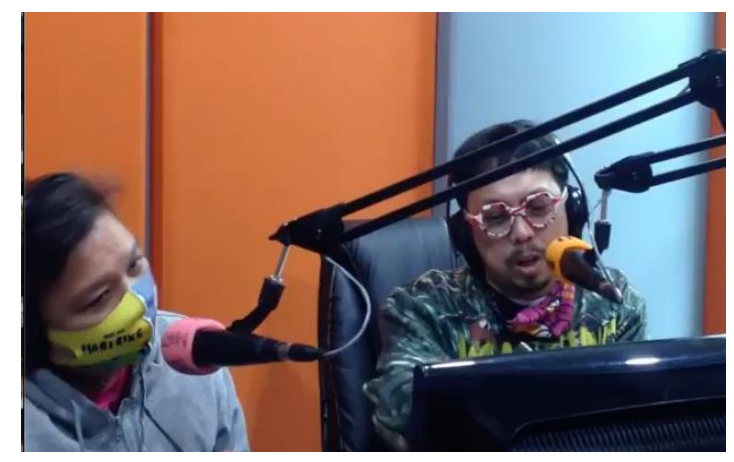

Gambar 2. Saat siaran berlangsung

Berdasarkan penelitian yang peneliti lakukan dengan cara wawancara dan observasi yang peneliti lakukan pada saat memproduksi program, dapat disimpulkan Tim Produksi program TikaUdjo menggunakan alat-alat teknologi dengan bijak dan bertanggung jawab.

Kendali Birokrasi. Penggunaan prosedur organisasi dan aturan-aturan formal seperti yang digambarkan (Weber). Pegawai diberikan sebuah buku panduan yang mencakup kebijakan yang harus diikuti, tinjauan laporan, tinjauan rapat dan tinjauan kinerja di gunakan untuk menyampaikan harapan yang lain. Aturan dalam suatu organisasi menjadi hal yang sangat penting, karena dengan adanya aturan-aturan, norma maupun prosedur dapat membentuk pegawai menjadi lebih baik, sesuai dengan apa yang diharapkan sebuah perusahaan atau instansi 
dan dengan adanya aturan yang jelas, maka pegawai tunduk demi tercapainya suatu visi dan misi organisasi.

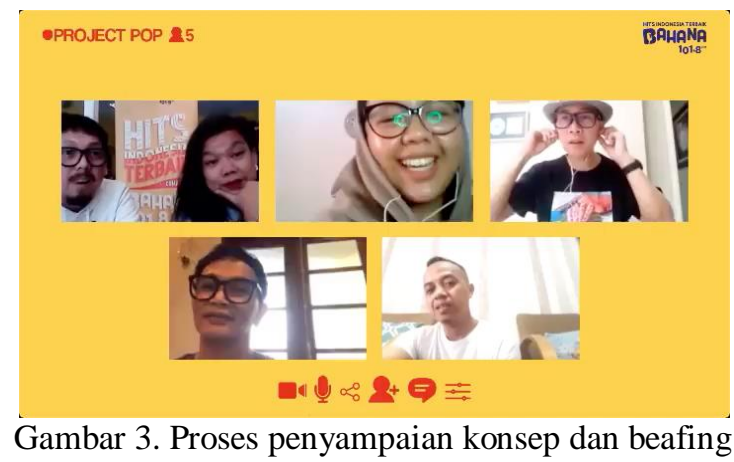

Peneliti menyimpulkan serangkaian kerja yang dilakukan Tim Produksi merupakan suatu kendali. Didalam meeting biasanya Tim Produksi yaitu, Produser, Assistent Produser dan dua orang Penyiar akan menentukan apa saja yang akan menjadi topik, isi dan konten untuk siaran dalam seminggu kedepan. Tema atau konten yang dipilih harus sesuai dengan segmentasi kebutuhan pendengar Radio Bahana. Setelah itu, Assistent Produser akan menyiapkan hasil meeting dan disetorkan kepada Produser. Setelah hasil meeting diberikan, Assistent Produser dan Prouser sama-sama mem follow up apa saja yang akan dibutuhkan Produser. Produser biasanya membutuhkan audio seperti Vox pop (Vox pop berupa dokumen audio yang mengumpulkan, berkat montase, jawaban sederet orang atas satu pertanyaan yang sama) untuk mendukung topik yang akan dibahas. Setelah itu Assistent Produser harus meminta acc dengan Produser untuk dikoreksi kembali. Jika ada yang tidak sesuai dengan apa yang direncakan biasanya Produser akan memberitahu kembali kepada Assistent Produser untuk mengganti konten atau isi sesuai dengan apa yang sudah disepakati bersama.

Kendali Konsertif (concertive control). Penggunaan hubungan interpesonal dan kerjasama tim sebagai sebuah cara kendali. Ini merupakan bentuk kendali yang paling sederhana karena mengandalkan pada realitas dan nilai - nilai bersama. Dalam organisasi, konsertif, aturan dan regulasi yang tertulis jelas digantikan oleh pemahaman pemaknaan nilai, objektif dan caracara penyampaian bersama, sejalan dengan apresiasi yang mendalam untuk "misi" organisasi. Pada kendali konsertif penggunaan hubungan interpersonal dan kerjasama tim merupakan sebuah cara kendali. Hal ini merupakan bentuk kendali yang paling sederhana karena mengandalkan pada realitas dan nilai-nilai bersama. Agar suatu organisasi lebih maju maka nilai keterbukaan perlu diterapkan oleh seluruh anggota organisasi. Dengan adanya keterbukaan berbagai masalah dapat diselesai- kan dengan cepat dan baik.

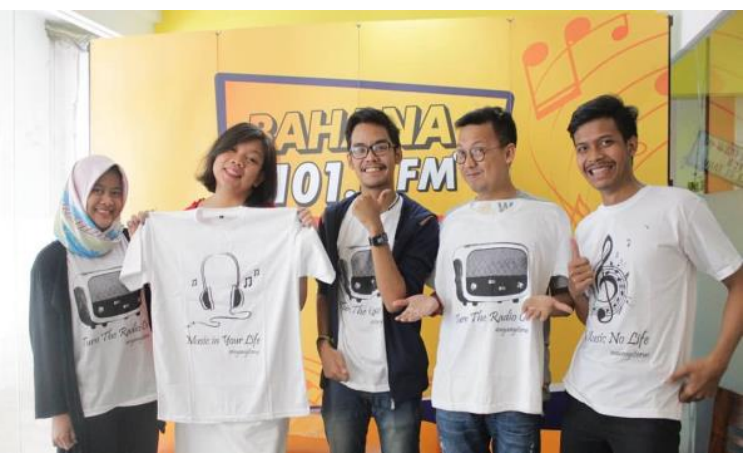

Gambar 4. dokumentasi penyiar dan anak magang 
Hubungan komunikasi yang terjadi antara anggota Tim Produksi program TikaUdjo Radio Bahana terhubung dengan baik. Mereka melakukan kerjasama tim yang baik untuk mencapai tujuan mereka. Tim Produksi pada program TikaUdjo menerapkan kendali konsertif untuk mencapai "misi" pada radionya. Salah satu Misi Radio bahana adalah menyajikan program acara yang bermutu untuk pendengar sesuai dengan target atau segmentasi radio bahana yaitu 25 - 34 years, untuk kalangan cewek maupun cowok, segmentasi kalangan B, C \& D di Greater JABODETABEK.

Tim Produksi Radio Bahana mampu menerapkan konsep teori kendali konsertif dengan baik dan kerjasama yang baik dalam melakukan sebuah produksi pada program acaranya. Hubungan interpersonal yang dilakukan oleh atasan bersama bawahan dilakukan dengan baik, begitu pun sebaliknya. Terbukti bagaimana solidnya tim produksi TikaUdjo hingga saat ini program tersebut masih di prosuderi oleh orang yang sama selama 5 tahun terakhir yaitu Ugi Lestari.

Selama saya magang dan berada di bawah beliau saya sangat terinspirasi bagaimana beliau Menyusun sebuh program dengan berdiskusi Bersama bahkan beliau sempat meminta pendapat pada penulis selaku anak magang yang membantu beliau dalam melakukan produksi dalam program TikaUdjo. Selain itu selaku penyiar TikaUdjo sangatlah humble dan ramah pada semua tim produksi, bahkan kami memanggil mereka dengan sebutan abah dan ambu sudah seperti keluarga sendiri. Dengan bukti-bukti tersebut maka penulis simpulkan bahwa proses kendali organisasi yang dilakukan oleh produser sangatlah berhasil.

\section{KESIMPULAN}

Berdasarkan hasil penelitian yang telah dilakukan mengenai "Kendali Organisasi Tim Produksi Program TikaUdjo 101,8 FM Radio Bahana Jakarta" dimana Tim Produksi merupakan salah satu kunci keberhasilan suatu program dengan fungsi yang dimiliki untuk mengelola program. Seorang pendengar atau audience juga menjadi acuan utama apakah layak atau tidak suatu program untuk bisa disiarkan. Penelitian ini menggunakan teori Kendali Organisasi Phillip Tomkins, George Cheney dan rekan-rekannya yang memiliki empat kendali yaitu Kendali Sederhana (simple control), Kendali Teknis (technical control), Kendali Birokrasi, dan Kendali Konsertif (concertive contol). Dalam melakukan penelitian penulis menggunakan metode wawancara mendalam (in depth interview) dan observasi mengenai Kendali Organisasi Tim Produksi Program TikaUdjo 101,8 FM Radio Bahana Jakarta. Hasil penelitian ini menyimpulkan bahwa Tim Produksi menerapkan empat kendali tesebut dengan baik. Langkah awal yang Tim Produksi lakukan dalam Kendali Sederhana adalah melakukan meeting mingguan atau diskusi untuk membahas isi dan konten apa yang akan disiarkan dalam siaran.

Berikutnya adalah kendali teknis pada saat produksi program, pada tahap ini kendali teknis sangat dibutuhkan. Pemakaian sejumlah fasilitas atau alat-alat teknologi sangat mempermudah Tim Produksi pada program TikaUdjo dalam menjalankan tugas mereka. Selanjutnya adalah birokrasi yang diterapkan pada Tim Produksi program TikaUdjo. Produser menghimbau kepada seluruh tim produksi yang bergabung dalam produksi siaran TikaUdjo untuk melakukan meeting setiap minggunya untuk menentukan isi dan konten apa saja yang harus disiapkan dalam seminggu kedepan senin sampai jumat. Tema atau konten yang dipilih

pasti harus sesuai. Setelah meeting Produser akan Menentukan dan menyepakati bersama tim konten apa yang akan disiarkan berdasarkan pertimbangan dan masukan tim.

Setelah itu, Tim Produksi program TikaUdjo menerapkan Kendali konsertif untuk mencapai "misi" Radio Bahana. Penggunaan hubungan interpesonal dan kerjasama tim 
merupakan sebuah cara kendali dalam organisasi atau tim kerja. Keberhasilan sebuah program radio merupakan hasil dari kerjasama Tim Produksi yang baik. Tim Produksi berperan penting dalam sebuah kualitas isi dan konten siaran radio. Serta mengetahui apa yang dibutuhkan oleh pendengar sesuai dengan target audience.

\section{DAFTAR PUSTAKA}

Bahana FM. (2020). Bahana FM. Bahana Fm. https://www.bahanafm.co.id/

Effendy, O. U. (2013). Ilmu Komunikasi Teori dan Praktek. PT Remaja Rosdakarya.

Hardjana, A. (2016). Komunikasi Organisasi Strategi dan Kompetensi. Kompas.

Littlejohn, S. W. (2009). Teori Komunikasi (9th ed.). Salemba.

Lubis, D. (2017). The Patterns of Use of Farmers Community Radio in West Java, Indonesia. 4531 ,

193-205. http://gssrr.org/index.php?journal=JournalOfBasicAndApplied\&page=article\&op=view \&path\%5B $\% 5 \mathrm{D}=6847 \&$ path $\% 5 \mathrm{~B} \% 5 \mathrm{D}=3317$

M, F. (2009). Ilmu Komunikasi Teori Dan Praktik. Graham Ilmu.

Maghfiroh, L. N., \& Syaf, H. (2019). Pengaruh Komunikasi Interpersonal Terhadap Kepuasan Pemustaka Di Upt Perpustakaan Universitas Stikubank ( Unisbank) Semarang. 50-64.

Masmuh, A. (2008). Komunikasi Organisasi dalam Perspektif Teori dan Praktek. UMM Press Muhammad.

Muhammad, A. (2007). Komunikasi Organisasi. Bumi Aksara.

Mulyana, D. (2005). Human Communication: prinsip - prinsip dasar. Remaja Rosdakarya.

Pingkan Agustine, Liliyana, H. Y. A. (2019). KENDALI ORGANISASI TIM PRODUKSI PROGRAM "BANGUN PAGI" DI 106,06 V RADIO JAKARTA. Rabit: Jurnal Teknologi Dan Sistem Informasi Univrab, 1(1), 2019. http://www.ghbook.ir/index.php?name= فر هنح نوين\&option=com_dbook\&task=readonline\&book_id=13650\&page=73\&chkhashk=ED9 C9491B4\&Itemid=218\&lang=fa\&tmpl=component\%0Ahttp://www.albayan.ae\%0Ahttp $\mathrm{s}: / /$ scholar.google.co.id/scholar?hl=en\&q=APLIKASI+PENGENA

Riswandi. (2009). Ilmu komunikasi. Graha Ilmu.

Sanityastuti, M. S. (1997). Pengantar Ilmu Komunikasi. Gunung Pesagi.

Sembiring, A. W., \& Sugianto, A. (2018). Peran Komunikasi Organisasi Terhadap Motivasi Kerja Karyawan Di Hotel Grandhika Setia Budi Medan. Jurnal Lensa Mutiara Komunikasi, 1(1), 29-44.

Sugiono. (2010). Metode Penelitian Kuantitatif, Kualitatif dan $R \& D$ (Bandung). Alfabeta. 